\title{
The Role of Rescue Therapies in the Treatment of Severe ARDS
}

\author{
Francesco Alessandri MD, Francesco Pugliese MD, and V Marco Ranieri MD
}

\author{
Introduction \\ Ventilation and PEEP \\ Recruitment Maneuvers \\ Fluid Management \\ Steroids \\ Neuromuscular Blocking Agents \\ High Frequency Oscillatory Ventilation \\ Selective Pulmonary Vasodilators \\ Prone Position \\ Extracorporeal Membrane Oxygenation \\ Summary
}

\begin{abstract}
ARDS is characterized by a non-cardiogenic pulmonary edema with bilateral chest radiograph opacities and hypoxemia refractory to oxygen therapy. It is a common cause of admission to the ICU due to hypoxemic respiratory failure requiring mechanical ventilation. Corticosteroids are not recommended in ARDS patients. Rescue therapies alleviate hypoxemia in patients unable to maintain reasonable oxygenation: recruitment maneuvers, prone positioning, inhaled nitric oxide, highfrequency oscillatory ventilation, and extracorporeal membrane oxygenation improve oxygenation, but their impact on mortality remains unproven. Restrictive fluid management seems to be a favorable strategy with no significant reduction in 60-d mortality. Future studies are needed to clarify the efficacy of these therapies on outcomes in patients with severe ARDS, and institution of these therapies may be considered on a case-by-case basis. Key words: severe ARDS; refractory hypoxemia; ventilatory setting; rescue therapies; extracorporeal membrane oxygenation; prone position. [Respir Care 2018;63(1):92-101. (C) 2018 Daedalus Enterprises]
\end{abstract}

\section{Introduction}

ARDS is a life-threatening condition that complicates a variety of critical illnesses, including sepsis, pneumonia, pancreatitis, and trauma. ${ }^{1}$ It is characterized by intense lung inflammation, progressive microatelectasis, diffuse alveolar damage, increased pulmonary vascular permeability, increased lung weight, and loss of aerated tissue. ${ }^{2}$ ARDS is clinically associated with severe hypoxemia, pa-

\footnotetext{
Drs Alessandri, Pugliese, and Ranieri are affiliated with Sapienza University of Rome, Department of Anesthesia and Critical Care Medicine, Policlinico Umberto I, Rome, Italy.
}

The authors have disclosed no conflicts of interest. tient-ventilator asynchrony, and high susceptibility to barotrauma and ventilator-induced lung injury (VILI). ${ }^{3}$

ARDS was first described 50 years ago by Ashbaugh and Petty ${ }^{4}$ in a case series of 12 patients who shared the common features of unusually persistent tachypnea and hypoxemia, opacification on chest radiographs, and poor lung compliance, despite different underlying causes. In 1994, the American and European Consensus Conference

Correspondence: Francesco Alessandri MD, Anesthesia and Intensive Care Medicine, Sapienza University of Rome, Policlinico Umberto I, Viale del Policlinico 155, 00161 Rome, Italy. E-mail: francesco.alessandri@uniroma1.it.

DOI: $10.4187 /$ respcare. 05752 
Table 1. The Berlin Definition of ARDS

\begin{tabular}{|c|c|}
\hline Factors & Criteria \\
\hline Timing & $\begin{array}{l}\text { Within } 1 \text { week of a known clinical insult or new } \\
\text { worsening respiratory symptoms }\end{array}$ \\
\hline Chest imaging & $\begin{array}{l}\text { Bilateral opacities not fully explained by } \\
\text { effusions lobar/lung collapse, or nodules }\end{array}$ \\
\hline Origin of edema & $\begin{array}{l}\text { Pulmonary edema not fully explained by cardiac } \\
\text { failure or fluid overload; objective assessment } \\
\text { (eg, echocardiography) is required to exclude } \\
\text { hydrostatic edema if no risk factor is present }\end{array}$ \\
\hline Oxygenation & Requires CPAP/PEEP $>5 \mathrm{~cm} \mathrm{H}_{2} \mathrm{O}$ \\
\hline Mild & $\mathrm{P}_{\mathrm{aO}_{2}} / \mathrm{F}_{\mathrm{IO}_{2}}=201-300 \mathrm{~mm} \mathrm{Hg}$ \\
\hline Moderate & $\mathrm{P}_{\mathrm{aO}_{2}} / \mathrm{F}_{\mathrm{IO}_{2}}=101-200 \mathrm{~mm} \mathrm{Hg}$ \\
\hline Severe & $\mathrm{P}_{\mathrm{aO}_{2}} / \mathrm{F}_{\mathrm{IO}_{2}} \leq 100 \mathrm{~mm} \mathrm{Hg}$ \\
\hline
\end{tabular}

proposed a new definition of ARDS that was globally accepted..$^{5}$ In 2012, this definition was revised by an international panel of experts and is now referred to as the Berlin definition of ARDS (Table 1). ${ }^{6}$ A recent large observational study $^{7}$ reported an ARDS prevalence of $10.4 \%$ of all ICU admissions and of $23.4 \%$ of all subjects receiving mechanical ventilation. ARDS appears to be underrecognized, undertreated, and associated with an especially high mortality rate of $46.1 \%$ for patients with severe ARDS.

The primary target for ARDS treatment is to ensure adequate gas exchange while minimizing the risk of VILI. To date, treatment is largely supportive, and mechanical ventilation remains the cornerstone. Some patients are unable to maintain adequate oxygenation despite being supported with conventional mechanical ventilation, and lifethreatening refractory hypoxemia may occur. Although a standard definition for refractory hypoxemia is a matter of ongoing debate, in most reports it has been defined as having a $\mathrm{P}_{\mathrm{aO}_{2}}<60 \mathrm{~mm} \mathrm{Hg}$, with an $\mathrm{F}_{\mathrm{IO}_{2}}$ of 0.8-1.0 and a $\mathrm{PEEP}>10-20 \mathrm{~cm} \mathrm{H} \mathrm{H}_{2} \mathrm{O}$ for $>12-24 \mathrm{~h}$. Under these circumstances, physicians may consider a number of supportive therapies, which are a final rescue attempt to prevent severe complications or death from hypoxemia (Fig. 1). Rescue therapies are only temporary methods that can support or replace respiratory function in patients with severe refractory respiratory failure on conventional mechanical ventilator support. Although these strategies improve oxygenation, their impact on mortality remains unproven, and they require a higher cost in terms of increased risk compared with standard care. Institution of these therapies may be considered on an individualized basis, and the choice will often be dictated by local availability and expertise..$^{8,9}$

\section{Ventilation and PEEP}

In a large study conducted by the ARDS Network, ${ }^{10}$ mortality was reduced and the number of ventilator-free days was greater in the group treated with lower tidal volumes $\left(\mathrm{V}_{\mathrm{T}} 6 \mathrm{~mL} / \mathrm{kg}\right.$ of predicted body weight) than in the group treated with traditional $\mathrm{V}_{\mathrm{T}}$. Decreasing plasma interleukin-6 (IL-6) concentrations, suggested that the group treated with lower $\mathrm{V}_{\mathrm{T}}$ had less lung inflammation. A reduced systemic inflammatory response to lung injury could contribute to the higher number of days without organ or system failure and the lower mortality in the group treated with lung-protective ventilation. ${ }^{10}$ As compared with conventional ventilation, the protective strategy was associated with a higher rate of weaning from mechanical ventilation and a lower rate of barotrauma in patients with ARDS, despite the use of higher PEEP levels and higher mean airway pressures. ${ }^{11}$ High levels of IL-8, IL-6, TNF- $\alpha$, IL- $1 \beta$ in bronchoalveolar lavage of patients with ARDS confirm the relevance of cytokines in the amplification of the inflammatory cascade leading to multiorgan failure and increasing mortality. Ranieri et al ${ }^{12}$ compared lung-protective ventilation with conventional ventilator strategy to evaluate the influence of mechanical ventilation on lung and systemic cytokine levels. The concentration of inflammatory mediators was lower $36 \mathrm{~h}$ after randomization in the lung-protective ventilation group than in the conventional strategy group. This lung-protective ventilation strategy aims to minimize VILI, which may result from alveolar overdistention or repeated opening and closing of individual lung units.

While in the past the choice of a specific mode of mechanical ventilation (pressure-controlled vs volume-controlled), was considered relevant for patient outcome, 2 recent meta-analyses were not able to show any significant difference in mortality, risk of barotrauma, or other physiologic responses. ${ }^{13,14}$ Despite the use of pressure- and volume-limited ventilatory strategies, lung injury may still persist or progress in some patients, resulting in worsening hypoxemia. ${ }^{15}$ Limited aerated lung tissue available to receive tidal ventilation consequently leads to regional hyperinflation and excessive stress; insufficient PEEP leads to excessive sheer injury.

Dependent lung regions of patients with ARDS contribute significantly to the development of hypoxemia because of shunts in perfused, nonaerated alveoli. Strategies to open this collapsed lung tissue may improve oxygenation and further reduce mortality. This especially may be an issue in patients receiving low $\mathrm{V}_{\mathrm{T}}$ ventilation in which a substantial portion of the lung may remain collapsed due to pressure and volume limitations. Terragni et al ${ }^{16}$ obtained pulmonary computed tomography at end-expiration and end-inspiration for 30 subjects treated with lung-protective ventilation. One third of subjects experienced substantial tidal hyperinflation with $\mathrm{V}_{\mathrm{T}} 6 \mathrm{~mL} / \mathrm{kg}$ predicted

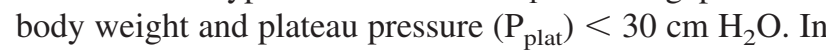
these subjects, the concentration of inflammatory mediators was higher and the number of ventilator-free days was lower than in the two thirds of subjects who experienced 


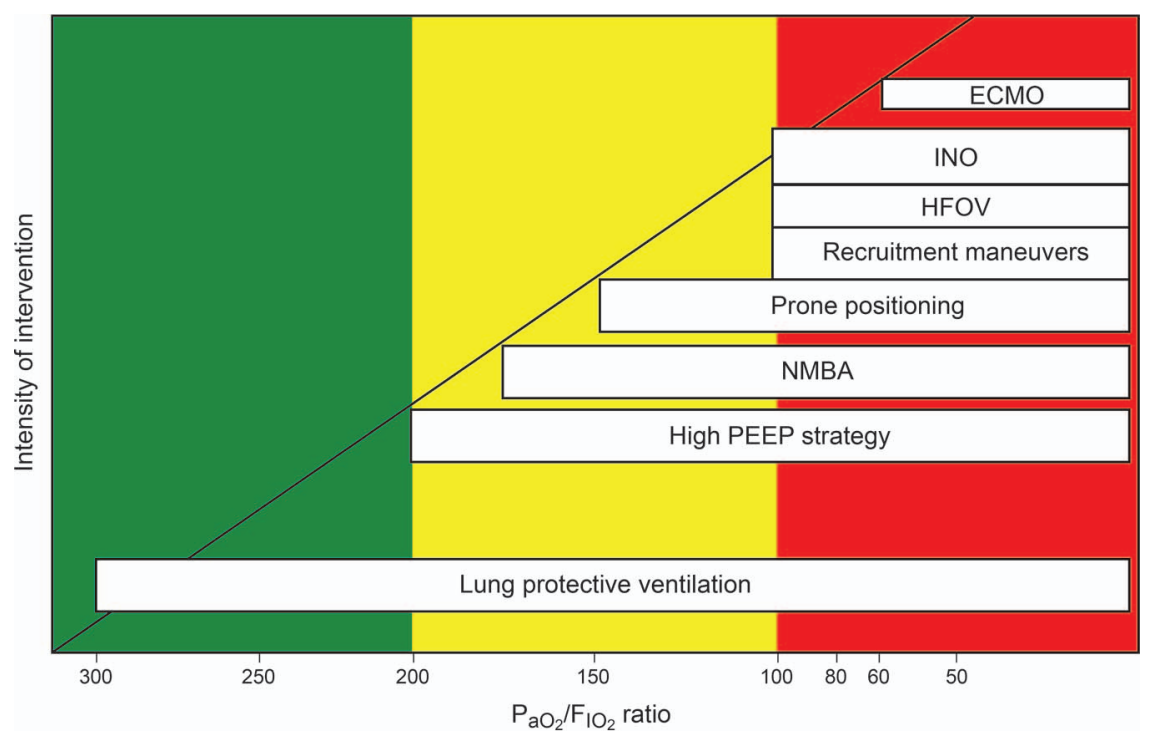

Fig. 1. Rescue therapy in increasing hypoxemia severity. Green indicates mild severity, yellow moderate severity, and red severe. ECMO = extracorporeal membrane oxygenation, HFOV = high-frequency oscillatory ventilation, INO = inhaled nitric oxide, NMBA = neuromuscular blocking agent.

less tidal hyperinflation. $\mathrm{P}_{\text {plat }}<28 \mathrm{~cm} \mathrm{H}_{2} \mathrm{O}$ were associated with less tidal hyperinflation than values of $\mathrm{P}_{\text {plat }}$ of $28-30 \mathrm{~cm} \mathrm{H}_{2} \mathrm{O}$. $\mathrm{P}_{\text {plat }}<28 \mathrm{~cm} \mathrm{H}_{2} \mathrm{O}$ seems to be associated with the more protective ventilatory settings. The ARDS Network settings may not be sufficient to minimize VILI in patients with ARDS whose disease process is characterized by a distribution of pulmonary lesions with a small, nondependent, normally aerated compartment and a large, dependent, nonaerated compartment. The proportion of nonaerated lung may be recruited by applying higher levels of PEEP than traditionally used $\left(5-12 \mathrm{~cm} \mathrm{H}_{2} \mathrm{O}\right)$ in the management of patients with ARDS. ${ }^{17,18}$ Amato et al ${ }^{19}$ postulated that cyclic strain predicts lung injury better than $\mathrm{V}_{\mathrm{T}}$. The functional lung size during disease is better quantified by the compliance of the respiratory system than by predicted body weight. Under such conditions, especially when the compliance of the respiratory system varies considerably among patients, cyclic strain, VILI, and survival should all be correlated with driving pressure rather than with $\mathrm{V}_{\mathrm{T}}$.

Although several experimental and observational studies found a beneficial effect for the use of higher PEEP in ARDS, 3 randomized trials, published between 2004 and 2008, did not show any difference in outcome between a low and a high PEEP ventilator strategy. ${ }^{20-22}$ However, when combining these data and considering only the subgroup of the most severe subjects $\left(\mathrm{P}_{\mathrm{aO}_{2}} / \mathrm{F}_{\mathrm{IO}_{2}}\right.$ $<200 \mathrm{~mm} \mathrm{Hg}$ ), the use of higher PEEP levels significantly decreased mortality. ${ }^{23}$ This suggests that the greater the severity (and the greater the amount of lung edema), the greater the positive effect of PEEP in reducing VILI. This has also been confirmed in an observational study, in which higher PEEP levels significantly reduced the opening and closing effects only in subjects with higher recruitability. ${ }^{24}$ However, the relationship between lung edema and recruitability has been questioned by Cressoni et al, ${ }^{25}$ who found that the PEEP levels necessary to keep the lung open were independent from total lung recruitability. These results suggest that recruitability depends also on the nature of edema, time of onset, and distribution of the disease within lung parenchyma.

Although several approaches have been proposed to tailor PEEP for the individual patient, the most common is to titrate PEEP according to an oxygenation/saturation target based on a PEEP/F $\mathrm{IO}_{2}$ table. ${ }^{21}$ In 1975, Suter et al ${ }^{16}$ coined the term best PEEP as the point at which the degree of lung recruitment is balanced with the risk of concomitant overdistention. The basis for determining the best PEEP is the quantification of recruitment: to increase PEEP by maintaining a constant $\mathrm{V}_{\mathrm{T}}$, not exceeding a safe limit of $\mathrm{P}_{\text {plat }}$ 26-28 $\mathrm{cm} \mathrm{H}_{2} \mathrm{O}$, or, after a recruitment maneuver, to decrease PEEP until a reduction of compliance appears. ${ }^{27}$ In a pooled sample of 3,562 subjects with ARDS ventilated with different combinations of $\mathrm{V}_{\mathrm{T}}$ and PEEP, the protective effects of higher PEEP were only seen when this was associated with decreased driving pressures, with a cutoff for increased mortality at a driving pressure of $15 \mathrm{~cm} \mathrm{H}_{2} \mathrm{O} .{ }^{19}$ Most important to this discussion was the fact that the relationship between mortality and high $\mathrm{P}_{\text {plat }}$ was observed only when driving pressure also was above $15 \mathrm{~cm} \mathrm{H}_{2} \mathrm{O}$. The airway driving pressure was the factor most associated with the outcome: higher mortality was only found when higher $\mathrm{P}_{\text {plat }}$ values were observed in subjects with higher driving pressures. 
Many techniques have been proposed to monitor lung recruitment, such as ultrasonography, electric impedance tomography, respiratory mechanics measurements, nitrogen washout techniques, and quantitative computed tomography scan, but none has yet gained general consensus or become routinely used in clinical settings. ${ }^{28-32}$

Despite the possible uncertainties regarding the endexpiratory absolute esophageal pressure as a reliable estimation of the pleural pressure, better oxygenation and compliance was achieved when PEEP was set according to an end-expiratory transpulmonary pressure of $0-10 \mathrm{~cm} \mathrm{H}_{2} \mathrm{O} .{ }^{33}$ An alternative to using the absolute value of esophageal pressure is to monitor how it changes due to adjustments in PEEP and $\mathrm{V}_{\mathrm{T}}$. This has been used to compute total end-inspiratory transpulmonary pressure, and it is a better marker of lung stress compared with $\mathrm{P}_{\text {plat }}$ in the presence of alterations in chest wall elastance. Setting high PEEP levels $(>15-18 \mathrm{~mm} \mathrm{Hg}$ ) should be accompanied by thorough hemodynamic assessment and might additionally be justified by transpulmonary pressure measurements and assessment of physiological dead space by volumetric capnography. ${ }^{34,35}$

\section{Recruitment Maneuvers}

Recruitment maneuvers are used as a strategy to improve oxygenation and reduce the risk of atelectrauma in patients with ARDS by re-opening and stabilizing collapsed lung regions. ${ }^{18}$ Several recruitment maneuvers have been proposed, including sustained inflations with CPAP values of $35-50 \mathrm{~cm} \mathrm{H}_{2} \mathrm{O}$ for $20-40 \mathrm{~s}$, incremental peak inspiratory pressures, lower $\mathrm{V}_{\mathrm{T}}$ (with sighs), intermittent sighs, stepwise increments in PEEP, and slow increases of inspiratory pressure to $40 \mathrm{~cm} \mathrm{H}_{2} \mathrm{O} .{ }^{36}$ Recruitment maneuvers attempt to increase the amount of aerated lung tissue to improve gas exchange. However, these may expose regions of healthy lung tissue to increased pressure and the risk of overdistention.

Several studies have shown improved gas exchange with recruitment maneuvers, but this did not translate into improved mortality. Benefits from recruitment maneuvers tend to be short-lived, and the increased airway pressure results in transient adverse events (eg, hypotension, hypoxemia) in a minority of patients. For example, in a recent systematic review, hypotension and decreased saturation occurred in $12 \%$ and $8 \%$ of subjects, respectively, during or after such maneuvers. ${ }^{18,36}$ However, persistent and severe adverse events related to recruitment maneuvers, such as the development of pneumothorax, remain rare. ${ }^{37}$ Moreover, studies to date have not elucidated the optimal technique, timing, and frequency of recruitment maneuvers. On the basis of currently available data, although routine recruitment maneuvers are not recommended to treat ARDS, such maneuvers can dramatically improve oxygenation in certain patients and should be considered as rescue therapy in patients with life-threatening refractory hypoxemia. ${ }^{38}$

\section{Steroids}

Steroids have positive immunomodulatory effects on inflammatory imbalance, reducing edema, hyaline membrane formation, surfactant depletion, and alveolar capillary membrane damage. ${ }^{39}$ High-dose and short-duration therapy (methylprednisolone $30 \mathrm{mg} / \mathrm{kg} / \mathrm{d}$ ) have demonstrated no improvement in mortality and an increased risk of infection. ${ }^{40} \mathrm{~A}$ recent meta-analysis investigating lower doses, instituted earlier and for longer duration, appeared to demonstrate improvements in lung function and decreased mortality. ${ }^{41}$ However, conclusive evidence about the use of steroids is lacking. Corticosteroids are not recommended as rescue therapy in patients with ARDS, because of improvements have been observed to be delayed and inconsistent. ${ }^{42}$

\section{Fluid Management}

ARDS is a protein-rich inflammatory lung edema into the interstitial space, often associated with a hydrostatic component. The increase in lung weight produces compression atelectasis and impairs lung mechanics and gas exchange. Pulmonary hypertension may be easily associated with increased pulmonary capillary pressure and cardiac failure. While the common mechanisms that cause edema are surgery and pleural effusion, lymphatic flow and capillary reabsorption into the venous side of the pulmonary capillary network are impaired by the positive intrathoracic pressure associated with mechanical ventilation. ${ }^{43}$ Excessive fluid administration leads to increased extravascular lung water, which is a poor prognostic marker in ARDS. Optimal fluid management provides dry lungs while maintaining organ perfusion.

An ARDS Network trial ${ }^{44}$ was designed to investigate risks and benefits of a fluid management protocol. Subjects with ARDS were randomized to conservative or liberal groups. The conservative group showed improved lung function compared with the liberal group, with fewer days on ventilation and ICU days without increasing non-pulmonary organ failures. There was no significant reduction in 60-d mortality. Over the first $7 \mathrm{~d}$, the liberal group had a fluid balance that increased approximately $1 \mathrm{~L} / \mathrm{d}$, whereas those in the conservative group fluid balance remained neutral.

In the subgroup of patients who are hypoproteinemic, there may be a role for accelerated edema clearance when pulmonary capillary permeability and hemodynamic stability is restored, because hypoproteinemic patients may be safely treated with a combination of albumin and fu- 
rosemide. Diuresis, weight loss, and normalization of serum protein concentrations may be achieved, and, over the first $24-48 \mathrm{~h}$ of therapy, the $\mathrm{P}_{\mathrm{aO}_{2}} / \mathrm{F}_{\mathrm{IO}_{2}}$ increased by $>60 \mathrm{~mm} \mathrm{Hg.}{ }^{45} \mathrm{~A}$ follow-up study of the same group also reported that $\mathrm{P}_{\mathrm{aO}_{2}} / \mathrm{F}_{\mathrm{IO}_{2}}$ increased by $>40 \mathrm{~mm} \mathrm{Hg}$ over 24-72 h compared to a decrease of 13-24 $\mathrm{mm} \mathrm{Hg}$ in the placebo group. ${ }^{46}$ These represent substantial improvements in oxygenation.

\section{Neuromuscular Blocking Agents}

Spontaneous breathing seems to be dangerous in patients with severe ARDS, whereas it appears to be beneficial in patients with mild to moderate ARDS. Neuromuscular blocking agents (NMBAs) should be reserved for the most severe cases to ensure patient-ventilator synchrony and prevent generation of a dangerously high transpulmonary pressure and VILI. ${ }^{47}$

Treatment with a continuous infusion of cisatracurium for $48 \mathrm{~h}$ early in the course of severe ARDS reduces 90-d mortality and barotraumas. It also increases the number of ventilator-free days and the number of days outside the ICU. In this context, the risk of ICU-acquired weakness is not increased. ${ }^{48}$ Early use of NMBAs decreases the proinflammatory response associated with ARDS and mechanical ventilation. The precise mechanism resulting in improved outcomes is not clear. Better synchrony may lead to more uniform lung recruitment and improved compliance, gas exchange, and systemic oxygenation. With respect to lung inflammation, it is plausible that improved control of inspiratory volumes and pressures reduces volutrauma, while better control of expiratory volumes and pressures reduces atelectrauma; the result is less pulmonary and systemic inflammation. ${ }^{49}$ These potential benefits must be weighed against prevailing concerns about NMBA therapy, including progressive atelectasis due to loss of diaphragmatic tone (with resultant hypoxemia) and, most important, ICU-acquired weakness. ${ }^{50}$

\section{High-Frequency Oscillatory Ventilation}

High-frequency oscillatory ventilation (HFOV) is a nonconventional mode that has been proposed to achieve the targets of protective ventilation with very low $\mathrm{V}_{\mathrm{T}}$ (equal to or less than the anatomical dead space) at a very high rate (3-6 Hz); sinusoidal flow oscillations are applied around a relatively constant mean airway pressure $\left(\overline{\mathrm{P}}_{\mathrm{aw}}\right)$. This strategy avoids overdistention of alveoli by delivering low $\mathrm{V}_{\mathrm{T}}$ (1-3 mL/kg), averting volutrauma, prevents end-expiratory alveolar collapse, and maintains alveolar recruitment by applying a constant $\overline{\mathrm{P}}_{\mathrm{aw}}$ to facilitate lung recruitment. ${ }^{51}$

HFOV theoretically achieves all goals pursued by lungprotective ventilation strategies; however, 2 large randomized clinical trials failed to prove any clinical benefit when
HFOV was applied in adults with moderate to severe ARDS as compared with a strategy with low $\mathrm{V}_{\mathrm{T}}$, high PEEP, and limited $\mathrm{P}_{\text {plat }}$. Young et al ${ }^{52}$ did not show any difference in mortality with HFOV compared to conventional mechanical ventilation, whereas Ferguson et al $^{53}$ reported an increase in mortality with HFOV. High $\overline{\mathrm{P}}_{\mathrm{aw}}$ suggests that overdistention of some lung regions without increased aeration of collapsed or flooded alveoli occurred, especially among subjects with heterogeneous and nonrecruitable lung. Increased mortality might also be due to the hemodynamic compromise implied by increased requirement of vasopressors and by the right ventricular failure secondary to a considerable increase in afterload. HFOV should not be used routinely in place of conventional lung-protective ventilation, and it should be reserved as a rescue therapy for those patients with refractory hypoxemia and in selected cases of severe ARDS. 54

The assessment of transpulmonary pressure by measuring esophageal pressure may represent a valid strategy to adopt more physiological $\overline{\mathrm{P}}_{\mathrm{aw}}$, reducing the risk of further lung injury and leading to maximal lung recruitment and minimal overdistention. ${ }^{55}$ The EPOCH Study (Clinical Trials.gov NCT02342756) is using this approach to adjust PEEP during conventional mechanical ventilation and $\overline{\mathrm{P}}_{\mathrm{aw}}$ during HFOV. ${ }^{56}$

\section{Selective Pulmonary Vasodilators}

Selective pulmonary vasodilators are commonly utilized for their therapeutic role in improving oxygenation in patients who have developed refractory hypoxemia in ARDS. ${ }^{57}$ These agents localize the drug to lung parenchyma capable of ventilation, improving ventilation-perfusion mismatch. Selective pulmonary vasodilators commonly used include inhaled nitric oxide (INO) and inhaled epoprostenol, a prostacyclin.

INO is a local vasodilator of capillary vessels in wellaerated alveoli, and it improves the ventilation-perfusion match in patients with ARDS and reduces pulmonary vascular resistance, which improves right ventricular output. ${ }^{58}$ The routine use of INO in ARDS is not recommended on the basis of current evidence, but it is frequently used in many institutions. The use of INO in subjects with ARDS showed no significant reduction in mortality. ${ }^{59}$ Use of INO could be considered when patients appear to be at great risk of imminent death from hypoxemia despite all other treatments. INO did not show significant beneficial effects on the duration of mechanical ventilation and stay in the ICU compared to the control group. ${ }^{59}$ Although INO improves oxygenation in the first $24 \mathrm{~h}$ by reducing ventilation-perfusion mismatch, over time it will induce vasodilatation of poorly ventilated areas, increasing ventilation-perfusion mismatch. ${ }^{60}$ 
Improved oxygenation is not associated with increased survival rates because the temporary improvement of oxygenation does not indicate improved lung function, reduction of lung injury, or resolution of the underlying cause of ARDS, including coexisting multi-organ damage. ${ }^{61}$ With the use of INO, the difference of pulmonary arterial pressure was initially significant on the first day but no longer present on days $2-4 .{ }^{61}$ Nitric oxide is as an important regulator of renal vascular tone and a modulator of glomerular function. When INO was first introduced, formation of methaemogloblin, production of reactive nitrogen species, hypotension, and platelet inhibition were the main collateral effects, while nephrotoxicity was not a major concern. ${ }^{62,63}$ Different studies demonstrated that INO increased the risk of renal injury among adult subjects with ARDS and potentially doubled the risk of renal replacement therapy. ${ }^{64}$ Therefore, changes in nitric oxide production could cause acute renal injury by altering the function of mitochondria, various enzymes, and deoxyribonucleic acid. Despite insufficient randomized controlled trials or meta-analyses, the combination therapies with prone positioning or HFOV may help in selected groups of patients or as a salvage therapy because they can enhance the effect of INO better than monotherapy alone. ${ }^{65}$

Inhaled epoprostenol has been suggested as an alternative to INO due to its similar efficacy, lower potential for systemic side effects, ease of administration, and substantially lower cost. Inhaled epoprostenol has been shown to significantly reduce pulmonary artery pressure and increase oxygenation. However, prostacyclin administration is technically challenging given its short half-life and susceptibility to photograph degradation. ${ }^{66}$ Since it was first publicized for the treatment of ARDS in 1993, efficacy data are lacking. ${ }^{57,67}$ Literature evaluating its use is lacking, and no studies have evaluated mortality as a primary end point. While commonly used as a therapy of final resort, a gap in the literature led to controversy surrounding inhaled epoprostenol with regard to optimal dosing and safety, as well as the target patient population. ${ }^{68,69}$ Iloprost, another selective pulmonary vasodilator traditionally used for treatment of pulmonary hypertension, has theoretical benefits in patients with ARDS, but there is minimal evidence to support its use for this indication. ${ }^{70}$

\section{Prone Position}

Prone position was first described 40 years ago as an alternative strategy to improve oxygenation in patients with ARDS. ${ }^{71}$ Several mechanisms have been proposed to explain this effect, including a redistribution of lung densities with a recruitment of dorsal regions, an increase in chest-wall elastance, a reduction in alveolar shunt, and a better ventilation/perfusion ratio. A more favorable distribution of stress and strain across a wider and more ho- mogenous territory (due to chest wall/lung shape matching of ventilation) reduces VILI and reverse right heart failure. As a consequence of lung recruitment, the reversal of hypoxemia and the reduction in driving pressure are the most reasonable explanations for the reduction in pulmonary vascular resistance and right heart dimensions during prone position. ${ }^{72}$ The shift in gravitational forces reduces atelectasis and minimizes compression of lung parenchyma by the heart and mediastinal structures, resulting in improved ventilation-perfusion matching. ${ }^{73}$

Earlier randomized trials showed inconsistent mortality benefit of prone positioning; however, these studies included all subjects with ARDS (from mild to severe), maintained prone position for $6 \mathrm{~h} / \mathrm{d}$, and did not apply protective mechanical ventilation. ${ }^{74,75}$ Despite these limitations, the survival rate increased among subjects with most severe ARDS treated in prone position. ${ }^{74}$ Subsequently, 2 trials, which enrolled more severe hypoxemic subjects with a longer period of prone positioning $(20 \mathrm{~h} / \mathrm{d})$, did not show any beneficial effects. ${ }^{76,77}$ However, a meta-analysis of previous studies suggested a significant survival benefit for subjects with $\mathrm{P}_{\mathrm{aO}_{2}} / \mathrm{F}_{\mathrm{IO}_{2}}<140 \mathrm{~mm} \mathrm{Hg}$ at admission. ${ }^{78}$ The PROSEVA trial ${ }^{79}$ was a multi-center randomized controlled trial on early application of prolonged prone position $(\geq 16 \mathrm{~h} / \mathrm{d})$ in subjects with severe ARDS. In this trial, ARDS severity was defined as $\mathrm{P}_{\mathrm{aO}_{2}} / \mathrm{F}_{\mathrm{IO}_{2}} \leq 150$ with PEEP $\geq 5 \mathrm{~cm} \mathrm{H}_{2} \mathrm{O}, \mathrm{F}_{\mathrm{IO}_{2}} \geq 0.6$, with an average $\mathrm{V}_{\mathrm{T}}$ of $6.1 \mathrm{~mL} / \mathrm{kg}$ of predicted body weight. The PROSEVA trial showed a major decrease in mortality rate at $28 \mathrm{~d}$ and $90 \mathrm{~d}$ in subjects treated with prone positioning. Early initiation of prone therapy appears to be an important factor for success. The process of moving a patient to a prone position can be labor-intensive and increases the risk of accidental removal of the endotracheal tube, drains, or catheters, as well as the development of pressure sores..$^{72}$ Although prone positioning presents some technical challenges, when it is performed by a skilled team, the adverse effects are relatively low and they are significantly overcome by the beneficial effects.

Contraindications to prone positioning must be considered, such as increased intracranial pressure or decreased cerebral perfusion, immediate need for a surgical or interventional procedure, recent thoracic surgery, recent facial trauma or surgery, hemodynamic instability, pregnancy or abdominal compartment syndrome, and unstable fractures of the spine, pelvis, or femur. ${ }^{80}$

\section{Extracorporeal Membrane Oxygenation}

In severe hypoxemia resistant to conventional treatment, including low-volume, low-pressure ventilation, prone position, INO, and HFOV, extracorporeal membrane oxygenation (ECMO) can be used as a rescue therapy by securing oxygenation as well as carbon dioxide removal 
while the lungs are resting with low ventilator pressure and low oxygen fraction. ${ }^{9}$

ECMO support is commonly performed via veno-venous access in which blood is drained via the superior or inferior vena cava and reinfused in the right atrium. ECMO is indicated when $\mathrm{P}_{\mathrm{aO}_{2}} / \mathrm{F}_{\mathrm{IO}_{2}}$ is $<80$, when $\mathrm{F}_{\mathrm{IO}_{2}}$ is $>90 \%$, and when the lung injury score is $3-4$; in this case, the risk of mortality exceeds $80 \% .{ }^{81}$ In the Berlin definition of ARDS, ECMO is proposed as a rescue therapy for severe hypoxemia when $\mathrm{P}_{\mathrm{aO}} / \mathrm{F}_{\mathrm{IO}_{2}}$ is $<50$. ECMO is considered when $\mathrm{P}_{\text {plat }}$ exceeds $32 \mathrm{~cm} \mathrm{H} \mathrm{H}_{2} \mathrm{O}, \mathrm{F}_{\mathrm{IO}_{2}}=100 \%, \mathrm{~S}_{\mathrm{pO}_{2}}<90 \%$, or $\mathrm{pH}<7.2$. $^{82}$

Indeed, once patients are on ECMO, blood can be well oxygenated with normal $\mathrm{P}_{\mathrm{aCO}}$ and neutral $\mathrm{pH}$; the goal of lung-protective ventilation is achieved and VILI is minimized. ${ }^{83}$ In patients with particularly severe ARDS who undergo ECMO, $\mathrm{V}_{\mathrm{T}}$ is significantly reduced by almost half, which leads to significant reduction in $\mathrm{P}_{\text {plat }}$ and derecruitment as PEEP remains stable. ${ }^{84}$ It can take a long time for some patients to re-open their lungs, and there could be a difficult balance between the risk of injury from lung overdistention and the risk of lung under-recruitment. ${ }^{84}$

Over the past few decades, most trials evaluating ECMO demonstrated no benefit because of several factors, including the prolonged interval between ARDS onset and assistance initiation, the poor oxygenation and $\mathrm{CO}_{2}$ removal capacities of devices used, and the high rate of technical complications such as significant bleeding resulting from intense anticoagulation required to overcome the poor biocompatibility of the circuits. ${ }^{85}$ Recently, however, significant progress has been made in the manufacture of ECMO circuits that are more biocompatible, perform at a higher level, and are more durable.

The United Kingdom-based Conventional Ventilation or ECMO for Severe Adult Respiratory Failure (CESAR) trial $^{86}$ and the good outcomes of subjects who received the latest generation of ECMO as rescue therapy during the influenza A (H1N1) influenza pandemic have reignited interest in ECMO for patients with severe ARDS. The CESAR trial in adult subjects with ARDS demonstrated an increase in 6-month survival from 50\% to $63 \%$ in the ECMO group, but the difference compared to the control group was not significant. When combining the mortality and the 6-month disability end points, the difference became significant in favor of the ECMO group. ${ }^{86}$ However, it is not possible to conclude that ECMO is superior to mechanical ventilation, because all subjects requiring ECMO were allocated only in one skilled center and the control group was not ventilated with a lung-protective strategy. ${ }^{87,88}$

Nevertheless, ECMO treatment has a place in clinical practice, as indicated by the Extracorporeal Life Support Organization International Registry Report, in which the number of adult ECMO treatments are expanding. ${ }^{89}$
The currently ongoing ECMO to Rescue Lung Injury in Severe ARDS trial is an international, multi-center, randomized controlled trial comparing conventional mechanical ventilation with prone positioning to ECMO in subjects with very severe ARDS (ie, $\mathrm{P}_{\mathrm{aO}_{2}} / \mathrm{F}_{\mathrm{IO}_{2}}<80 \mathrm{~mm} \mathrm{Hg}$ ). ${ }^{90}$ Early initiation of an ECMO strategy might decrease mortality from $45-50 \%$ to $<20 \%$, with potentially less cognitive and psychiatric impairment and improved health-related quality of life in long-term survivors. ${ }^{91}$ The possible benefits of extracorporeal support have to be balanced against dangerous complications such as bleeding, thrombosis, infection, and distal limb ischemia. ${ }^{83}$ There is no absolute contraindication for ECMO; all cases have to be discussed, and indications and limits will likely change as future studies are performed.

\section{Summary}

ARDS is a syndrome caused by different diseases and leads to life-threatening refractory hypoxemia. A continuous escalation of therapies may be considered on an individualized basis. Despite several decades of investigation into potential treatment strategies, use of lung-protective ventilation with $\mathrm{V}_{\mathrm{T}}$ of $6 \mathrm{~mL} / \mathrm{kg}$ predicted body weight and $\mathrm{P}_{\text {plat }}$ $<30 \mathrm{~cm} \mathrm{H}_{2} \mathrm{O}$ remains the only proven therapy to decrease mortality in ARDS. An oxygenation/saturation target based on a PEEP/ $/ \mathrm{FO}_{2}$ table is a common approach to set PEEP, but a relationship between mortality and high $\mathrm{P}_{\text {plat }}$ was observed only when driving pressure also was above $15 \mathrm{~cm} \mathrm{H}_{2} \mathrm{O}$. In patients with ARDS, recruitment maneuvers improve oxygenation, but this is a temporary approach that doesn't improve mortality. Evidence supporting steroid use is lacking, and a conservative fluid balance is not superior to a liberal one. NMBAs ensure uniform lung recruitment, prevent generation of dangerous high transpulmonary pressure, and decrease the pro-inflammatory response associated with ARDS, but this approach must be provided within the first $48 \mathrm{~h}$ to prevent diaphragm atrophy and ICU-acquired weakness. HFOV theoretically achieves all of the goals of lung-protective ventilation strategies, however, randomized clinical trials failed to prove any clinical benefit. INO temporarily improves oxygenation, but it is not associated with an increased survival rate and hasn't shown any benefit to lung function. Prone positioning in patients with severe ARDS promotes a shift in gravitational forces, minimizes compression of lung parenchyma by the heart and mediastinal structures, and improves ventilation-perfusion matching. ECMO is being increasingly used to support critically ill adults who have failed conventional management, and it may be an effective salvage treatment for patients with ARDS presenting with rapid refractory respiratory failure; however, controlled trials are needed to better define indications and best practices for this therapy. 


\section{Rescue Therapies For SEVERE ARDS}

\section{REFERENCES}

1. Ware LB, Matthay MA. The acute respiratory distress syndrome. N Engl J Med 2000;342(18):1334-49.

2. Pugin J, Verghese G, Widmer M-C, Matthay MA. The alveolar space is the site of intense inflammatory and profibrotic reactions in the early phase of acute respiratory distress syndrome. Crit Care Med 1999;27(2):304-12.

3. Slutsky AS, Ranieri VM. Ventilator-induced lung injury. N Engl J Med 2013;369(22):2126-36.

4. Ashbaugh DG, Bigelow DB, Petty TL, Levine BE. Acute respiratory distress in adults. Lancet 1967;2(7511):319-23.

5. Bernard GR, Artigas A, Brigham KL, Carlet J, Falke K, Hudson L, et al. The American-European Consensus Conference on ARDS: definitions, mechanisms, relevant outcomes, and clinical trial coordination. Am J Respir Crit Care Med 1994;149(3 Pt1):818-24.

6. Ranieri VM, Rubenfeld GD, Thompson BT, Ferguson ND, Caldwell E, Fan E, et al. Acute respiratory distress syndrome: the Berlin Definition. JAMA 2012;307(23):2526-33.

7. Bellani G, Laffey JG, Pham T, Fan E, Brochard L, Esteban A, et al. Epidemiology, patterns of care, and mortality for patients with acute respiratory distress syndrome in intensive care units in 50 countries. JAMA 2016;315(8):788-800.

8. Moerer O, Tonetti T, Quintel M. Rescue therapies for acute respiratory distress syndrome: what to try first? Curr Opin Crit Care 2017;23(1):52-59

9. Bein T, Grasso S, Moerer O, Quintel M, Guerin C, Deja M, et al. The standard of care of patients with ARDS: ventilatory settings and rescue therapies for refractory hypoxemia. Intensive Care Med 2016; 42(5):699-711.

10. Brower RG, Matthay MA, Morris A, Schoenfeld D, Thompson BT, Wheeler A. Ventilation with lower tidal volumes as compared with traditional tidal volumes for acute lung injury and the acute respiratory distress syndrome. N Engl J Med 2000;342(18):1301-08.

11. Amato MBP, Barbas CSV, Medeiros DM, Magaldi RB, Schettino GDP, Filho GL, et al. Effect of a protective-ventilation strategy on mortality in the acute respiratory distress syndrome. N Engl J Med 1998;338(6):347-54.

12. Ranieri VM, Suter PM, Tortorella C, De Tullio R, Dayer JM, Brienza $\mathrm{A}$, et al. Effect of mechanical ventilation on inflammatory mediators in patients with acute respiratory distress syndrome. JAMA 1999; 281(1):54-61.

13. Chacko B, Peter JV, Tharyan P, John G, Jeyaseelan L. Pressurecontrolled versus volume-controlled ventilation for acute respiratory failure due to acute lung injury (ALI) or acute respiratory distress syndrome (ARDS). Cochrane Database Syst Rev 2015;1:CD008807.

14. Rittayamai N, Katsios CM, Beloncle F, Friedrich JO, Mancebo J, Brochard L. Pressure-controlled vs. volume-controlled ventilation in acute respiratory failure: a physiology-based narrative and systematic review. Chest 2015;148(2):340-55.

15. Diaz JV, Brower R, Calfee CS, Matthay MA. Therapeutic strategies for severe acute lung injury. Crit Care Med 2010;38(8):1644-50.

16. Terragni PP, Rosboch G, Tealdi A, Corno E, Menaldo E, Davini O, et al. Tidal hyperinflation during low tidal volume ventilation in acute respiratory distress syndrome. Am J Respir Crit Care Med 2007;175(2):160-66.

17. Thompson BT, Hayden D, Matthay MA, Brower R, Parsons PE. Clinicians' approaches to mechanical ventilation in acute lung injury and ARDS. Chest 2001;120(5):1622-27.

18. Gattinoni L, Caironi P, Cressoni M, Chiumello D, Ranieri VM, Quintel M, et al. Lung recruitment in patients with the acute respiratory distress syndrome. N Engl J Med 2006;354(17):1775-86.

19. Amato MB, Meade MO, Slutsky AS, Brochard L, Costa EL, Schoenfeld DA, et al. Driving pressure and survival in the acute respiratory distress syndrome. N Engl J Med 2015;372(8):747-55.
20. Mercat A, Richard J-CM, Vielle B, Jaber S, Osman D, Diehl J-L, et al. Positive end-expiratory pressure setting in adults with acute lung injury and acute respiratory distress syndrome: a randomized controlled trial. JAMA 2008;299(6):646-55.

21. Brower RG, Lanken PN, MacIntyre N, Matthay MA, Morris A, Ancukiewicz M, et al. Higher versus lower positive end-expiratory pressures in patients with the acute respiratory distress syndrome. N Engl J Med 2004;351(4):327-36.

22. Meade MO, Cook DJ, Guyatt GH, Slutsky AS, Arabi YM, Cooper DJ, et al. Ventilation strategy using low tidal volumes, recruitment maneuvers, and high positive end-expiratory pressure for acute lung injury and acute respiratory distress syndrome: a randomized controlled trial. JAMA 2008;299(6):637-45.

23. Briel M, Meade M, Mercat A, Brower RG, Talmor D, Walter SD, et al. Higher vs lower positive end-expiratory pressure in patients with acute lung injury and acute respiratory distress syndrome: systematic review and meta-analysis. JAMA 2010;303(9):865-73.

24. Caironi P, Cressoni M, Chiumello D, Ranieri M, Quintel M, Russo SG, et al. Lung opening and closing during ventilation of acute respiratory distress syndrome. Am J Respir Crit Care Med 2010; 181(6):578-86.

25. Cressoni M, Chiumello D, Carlesso E, Chiurazzi C, Amini M, Brioni $\mathrm{M}$, et al. Compressive forces and computed tomography-derived positive end-expiratory pressure in acute respiratory distress syndrome. Anesthesiology 2014;121(3):572-81.

26. Suter PM, Fairley B, Isenberg MD. Optimum end-expiratory airway pressure in patients with acute pulmonary failure. N Engl J Med 1975;292(6):284-89.

27. Rodriguez PO, Bonelli I, Setten M, Attie S, Madorno M, Maskin LP, et al. Transpulmonary pressure and gas exchange during decremental PEEP titration in pulmonary ARDS patients. Respir Care 2013;58(5): 754-63.

28. Bouhemad B, Brisson H, Le-Guen M, Arbelot C, Lu Q, Rouby JJ. Bedside ultrasound assessment of positive end-expiratory pressureinduced lung recruitment. Am J Respir Crit Care Med 2011;183(3): 341-47.

29. Cinnella G, Grasso S, Raimondo P, D'Antini D, Mirabella L, Rauseo M, Dambrosio M. Physiological effects of the open lung approach in patients with early, mild diffuse acute respiratory distress syndrome: an electrical impedance tomography study. Anesthesiology 2015; 123(5):1113-21.

30. Chiumello D, Marino A, Brioni M, Cigada I, Menga F, Colombo A, et al. Lung recruitment assessed by respiratory mechanics and computed tomography in patients with acute respiratory distress syndrome. What is the relationship? Am J Respir Crit Care Med 2016; 193(11):1254-63.

31. Chiumello D, Cressoni M, Chierichetti M, Tallarini F, Botticelli M, Berto V, et al. Nitrogen washout/washin, helium dilution and computed tomography in the assessment of end expiratory lung volume. Critical Care 2008;12(6):1-8.

32. Godet T, Constantin JM, Jaber S, Futier E. How to monitor a recruitment maneuver at the bedside. Curr Opin Crit Care 2015;21(3): 253-58.

33. Talmor D, Sarge T, Malhotra A, O'Donnell CR, Ritz R, Lisbon A, et al. Mechanical ventilation guided by esophageal pressure in acute lung injury. N Engl J Med 2008;359(20):2095-104.

34. Mauri T, Yoshida T, Bellani G, Goligher EC, Carteaux G, Rittayamai N, et al. Esophageal and transpulmonary pressure in the clinical setting: meaning, usefulness and perspectives. Intensive Care Med 2016;42(9):1360-73.

35. Suarez-Sipmann F, Bohm SH, Tusman G. Volumetric capnography: the time has come. Curr Opin Crit Care 2014;20(3):333-39. 


\section{Rescue Therapies For SEVERE ARDS}

36. Fan E, Wilcox ME, Brower RG, Stewart TE, Mehta S, Lapinsky SE, et al. Recruitment maneuvers for acute lung injury: a systematic review. Am J Respir Crit Care Med 2008;178(11):1156-63.

37. Fan E, Checkley W, Stewart TE, Muscedere J, Lesur O, Granton JT, et al. Complications from recruitment maneuvers in patients with acute lung injury: secondary analysis from the lung open ventilation study. Respir Care 2012;57(11):1842-49.

38. Alhurani RE, Oeckler RA, Franco PM, Jenkins SM, Gajic O, Pannu SR. Refractory hypoxemia and use of rescue strategies: a U.S. national survey of adult intensivists. Ann Am Thorac Soc 2016;13(7): 1105-14.

39. Peter JV, John P, Graham PL, Moran JL, George IA, Bersten A. Corticosteroids in the prevention and treatment of acute respiratory distress syndrome (ARDS) in adults: meta-analysis. BMJ 2008; 336(7651):1006-09.

40. Bernard GR, Luce JM, Sprung CL, Rinaldo JE, Tate RM, Sibbald WJ, et al. High-dose corticosteroids in patients with the adult respiratory distress syndrome. N Engl J Med 1987;317(25):1565-70.

41. Meduri GU, Bridges L, Shih MC, Marik PE, Siemieniuk RA, Kocak M. Prolonged glucocorticoid treatment is associated with improved ARDS outcomes: analysis of individual patients' data from four randomized trials and trial-level meta-analysis of the updated literature. Intensive Care Med 2016;42(5):829-40.

42. Thompson BT, Ranieri VM. Steroids are part of rescue therapy in ARDS patients with refractory hypoxemia: no. Intensive Care Med 2016;42(5):921-23.

43. Neamu RF, Martin GS. Fluid management in acute respiratory distress syndrome. Curr Opin Crit Care 2013;19(1):24-30.

44. Wiedemann HP, Wheeler AP, Bernard GR, Thompson BT, Hayden D, de Boisblanc B, on behalf of National Heart, Lung, and Blood Institute Acute Respiratory Distress Syndrome (ARDS) Clinical Trials Network. Comparison of two fluid-management strategies in acute lung injury. N Engl J Med 2006;354(24):2564-75.

45. Martin GS, Mangialardi R, Wheeler AP, Dupont WD, Morris JA, Bernard GR. Albumin and furosemide therapy in acute lung injury. Crit Care Med 2002;30(10):2175-81.

46. Martin GS, Moss M, Wheeler AP, Mealer M, Morris JA, Bernard GR. Crit Care Med 2005;33(8):1681-87.

47. Grawe ES, Bennett S, Hurford WE. Early paralysis for the management of ARDS. Respir Care 2016;61(6):830-38.

48. Papazian L, Forel JM, Gacouin A, Penot-Ragon C, Perrin G, Loundou A. Neuromuscular blockers in early acute respiratory distress syndrome. N Engl J Med 2010;363(12):1107-16.

49. Alhazzani W, Alshahrani M, Jaeschke R, Forel JM, Papazian L, Sevransky J, Meade MO. Neuromuscular blocking agents in acute respiratory distress syndrome: a systematic review and meta-analysis of randomized controlled trials. Crit Care 2013;17(2):R43.

50. Garnacho-Montero J, Madrazo-Osuna J, Garcia-Garmendia JL, Ortiz-Leyba C, Jimenez-Jimenez FJ, Barrero-Almodovar A, et al. Critical illness polyneuropathy: risk factors and clinical consequences: a cohort study in septic patients. Intensive Care Med 2001;27(8):128896.

51. Facchin F, Fan E. Airway pressure release ventilation and highfrequency oscillatory ventilation: potential strategies to treat severe hypoxemia and prevent ventilator-induced lung injury. Respir Care 2015;60(10):1509-21.

52. Ferguson ND, Cook DJ, Guyatt GH, Mehta S, Hand L, Austin P, et al. High-frequency oscillation in early acute respiratory distress syndrome. N Engl J Med 2013;368(9):795-805.

53. Young D, Lamb SE, Shah S, MacKenzie I, Tunnicliffe W, Lall R, et al. High-frequency oscillation for acute respiratory distress syndrome. N Engl J Med 2013;368(9):806-13.
54. Nguyen AP, Schmidt UH, MacIntyre NR. Should high-frequency ventilation in the adult be abandoned? Respir Care 2016;61(6):791800

55. Guervilly C, Forel JM, Hraiech S, Roch A, Talmor D, Papazian L. Effect of high-frequency oscillatory ventilation on esophageal and transpulmonary pressures in moderate-to-severe acute respiratory distress syndrome. Ann Intensive Care 2016;6(1):84.

56. Fan E, Facchin F. Esophageal Pressure-Guided Optimal PEEP/mPaw in CMV and HFOV: The EPOCH Study. ClinicalTrials.gov ID NCT02342756

57. Walmrath D, Schneider T, Pilch J, Grimminger F, Seeger W. Aerosolised prostacyclin in adult respiratory distress syndrome. Lancet 1993;342(8877):961-62.

58. Griffiths MJ, Evans TW. Inhaled nitric oxide therapy in adults. N Engl J Med 2005;353(25):2683-95.

59. Adhikari NK, Dellinger RP, Lundin S, Payen D, Vallet B, Gerlach $\mathrm{H}$, et al. Inhaled nitric oxide does not reduce mortality in patients with acute respiratory distress syndrome regardless of severity: systematic review and meta-analysis. Crit Care Med 2014;42(2):404-12.

60. Gerlach H, Keh D, Semmerow A, Busch T, Lewandowski K, Pappert $\mathrm{DM}$, et al. Dose-response characteristics during long-term inhalation of nitric oxide in patients with severe acute respiratory distress syndrome: a prospective, randomized, controlled study. Am J Respir Crit Care Med 2003;167(7):1008-15.

61. Afshari A, Brok J, Moller AM, Wetterslev J. Inhaled nitric oxide for acute respiratory distress syndrome and acute lung injury in adults and children: a systematic review with meta-analysis and trial sequential analysis. Anesth Analg 2011;112(6):1411-21.

62. Germann P, Braschi A, Della Rocca G, Dinh-Xuan AT, Falke K, Frostell $\mathrm{C}$, et al. Inhaled nitric oxide therapy in adults: European expert recommendations. Intensive Care Med 2005;31(8):1029-41.

63. McMahon TJ, Doctor A. Extrapulmonary effects of inhaled nitric oxide: role of reversible S-nitrosylation of erythrocytic hemoglobin. Proc Am Thorac Soc 2006;3(2):153-60.

64. Ruan SY, Wu HY, Lin HH, Wu HD, Yu CJ, Lai MS. Inhaled nitric oxide and the risk of renal dysfunction in patients with acute respiratory distress syndrome: a propensity-matched cohort study. Crit Care 2016;20(1):389.

65. Fan E, Mehta S. High-frequency oscillatory ventilation and adjunctive therapies: inhaled nitric oxide and prone positioning. Crit Care Med 2005;33(Suppl 3):S182-87.

66. Lowson SM. Inhaled alternatives to nitric oxide. Anesthesiology 2002;96:1504-13

67. Bein T, Pfeifer M, Riegger GA, Taeger K. Continuous intraarterial measurement of oxygenation during aerosolized prostacyclin administration in severe respiratory failure. N Engl J Med 1994;331(5): $335-36$.

68. Dunkley K, Louzon P, Lee J, Vu S. Efficacy, safety, and medication errors associated with the use of inhaled epoprostenol for adults with acute respiratory distress syndrome: a pilot study. Ann Pharmacother 2013;47(6):790-96.

69. Domenighetti G, Stricker H, Waldispuehl B. Nebulized prostacyclin (PGI2) in acute respiratory distress syndrome: impact of primary (pulmonary injury) and secondary (extrapulmonary injury) disease on gas exchange response. Crit Care Med 2001;29(1):57-62

70. Sawheny E, Ellis A, Kinasewitz G. Iloprost improves gas exchange in patients with pulmonary hypertension and ARDS. Chest 2013; 144(1):55-62

71. Piehl MA, Brown RS. Use of extreme position changes in acute respiratory failure. Crit Care Med 1976;4(1):13-14.

72. Kallet RH. A comprehensive review of prone position in ARDS. Respir Care 2015;60(11):1660-87. 


\section{Rescue Therapies for Severe ARDS}

73. Marini JJ, Josephs SA, Mechlin M, Hurford WE. Should early prone positioning be a standard of care in ARDS with refractory hypoxemia? Respir Care 2016;61(6):818-29.

74. Gattinoni L, Tognoni G, Pesenti A, Taccone P, Mascheroni D, Labarta $\mathrm{V}$, et al. Effect of prone positioning on the survival of patients with acute respiratory failure. N Engl J Med 2001;345(8):568-73.

75. Guerin C, Gaillard S, Lemasson S et al. Effects of systematic prone positioning in hypoxemic acute respiratory failure: a randomized controlled trial. JAMA 2004;292(19):2379-87.

76. Mancebo J, Fernández R, Blanch L, Rialp G, Gordo F, Ferrer M, et al. A multicenter trial of prolonged prone ventilation in severe acute respiratory distress syndrome. Am J Respir Crit Care Med 2006; 173(11):1233-39.

77. Taccone P, Pesenti A, Latini R, Polli F, Vagginelli F, Mietto C, et al. Prone positioning in patients with moderate and severe acute respiratory distress syndrome: a randomized controlled trial. JAMA 2009; 302(18):1977-84.

78. Sud S, Friedrich JO, Taccone P, Polli F, Adhikari NKJ, Latini R, et al. Prone ventilation reduces mortality in patients with acute respiratory failure and severe hypoxemia: systematic review and metaanalysis. Intensive Care Med 2010;36(4):585-99.

79. Guerin C, Reignier J, Richard J-C, Beuret P, Gacouin A, Boulain T, et al. Prone positioning in severe acute respiratory distress syndrome. N Engl J Med 2013;368(23):2159-68.

80. Gattinoni L, Taccone P, Carlesso E, Marini JJ. Prone position in acute respiratory distress syndrome: rationale, indications, and limits. Am J Respir Crit Care Med 2013;188(11):1286-93.

81. Hubmayr RD, Farmer JC. Should we "rescue" patients with 2009 influenza $\mathrm{A}(\mathrm{H} 1 \mathrm{~N} 1)$ and lung injury from conventional mechanical ventilation? Chest 2010;137(4):745-47.

82. Ferguson ND, Fan E, Camporota L, Antonelli M, Anzueto A, Beale $\mathrm{R}$, et al. The Berlin definition of ARDS: an expanded rationale, justification, and supplementary material Intensive Care Med 2012; 38(10):1573-82.

83. Schuerer DJ, Kolovos NS, Boyd KV, Coopersmith CM. Extracorporeal membrane oxygenation: current clinical practice, coding, and reimbursement. Chest 2008;134(1):179-84.

84. Pham T, Combes A, Rozé H, Chevret S, Mercat A, Roch A, et al. Extracorporeal membrane oxygenation for pandemic influenza A(H1N1)-induced acute respiratory distress syndrome: a cohort study and propensity-matched analysis. Am J Respir Crit Care Med 2013; 187(3):276-85.

85. Zapol WM, Snider MT, Hill JD, Fallat RJ, Bartlett RH, Edmunds $\mathrm{LH}$, et al. Extracorporeal membrane oxygenation in severe acute respiratory failure. A randomized prospective study. JAMA 1979; 242(20):2193-96.

86. Peek GJ, Mugford M, Tiruvoipati R, Wilson A, Allen E, Thalanany $\mathrm{MM}$, et al. Efficacy and economic assessment of conventional ventilator support versus extracorporeal membrane oxygenation for severe adult respiratory failure (CESAR): a multicentre randomised controlled trial. Lancet 2009;374(9698):1351-63.

87. Ventetuolo CE, Muratore CS. Extracorporeal life support in critically ill adults. Am J Respir Crit Care Med 2014;190(5):497-508.

88. Moran JL, Chalwin RP, Graham PL. Extracorporeal membrane oxygenation (ECMO) reconsidered. Crit Care Resusc 2010;12(2):13135.

89. Thiagarajan RR, Barbaro RP, Rycus PT, Mcmullan DM, Conrad SA, Fortenberry JD, Paden ML, ELSO member centers. Extracorporeal Life Support Organization registry international report 2016. ASAIO J 2017;63(1):60-67.

90. ClinicalTrials.gov. Extracorporeal Membrane Oxygenation for Severe Acute Respiratory Distress syndrome (EOLIA). [Online]. Registration NCT01470703.

91. Combes A, Ranieri M. Rescue therapy for refractory ARDS should be offered early: yes. Intensive Care Med 2015;41(5):923-25. 